\title{
Cenas sociais e espaço de trabalho \\ Homologias na vida profissional de jovens de classes populares
}

\author{
Alicia Beatriz Gutiérrez e Gonzalo Assusa \\ Tradução do espanhol de Renata Oliveira Rufino
}

Introdução

De acordo com os cânones da sociologia, o mundo moderno foi construído como um conjunto mais ou menos definido de âmbitos, mundos ou esferas com lógicas relativamente constituídas de coordenação e complementaridade. As ciências sociais foram organizadas em disciplinas seguindo este esquema: uma ciência da política, uma ciência da sociedade, uma da cultura, uma da economia. Considerando o âmbito profissional como uma dessas esferas, os estudos sobre o mundo do trabalho têm comumente incorrido nessa visão compartimentada da realidade social, vinculada ao performativo discurso (moderno) sobre a modernidade.

Algumas das tentativas de aprofundar na indagação socioantropológica sobre a lógica interna dessas esferas e de reconstruir suas ordens interacionais produziram contribuições valiosas, apesar de carecerem de ferramentas conceituais relevantes para propor explicações articuladoras sobre essas separações práticas - que provocam separações sedimentadas estruturalmente - entre âmbitos diferenciais de ação e posições estruturais relativas à distribuição desigual dos recursos sociais. Da identificação dessa área de relativo vazio, parte o nosso texto.

A partir da descrição de uma série de situações problemáticas em espaços de trabalho nos quais atuam jovens de classes populares da cidade de Córdoba (Argentina), mostraremos as múltiplas justaposições, entrecruzamentos, superposições e atravessamentos que ocorrem cotidianamente entre diferentes cenas sociais e o 
âmbito específico do trabalho. Depois, relacionando as diferentes justaposições com as desigualdades constitutivas do espaço das classes sociais, proporemos uma interpretação dos deslocamentos de lógicas de ação e critérios de valor entre cenas sociais como estratégias de gestão de recursos no âmbito do trabalho, possibilitados por homologias estruturais entre diferentes cenas.

Esta análise enquadra-se em uma pesquisa mais ampla sobre as estratégias familiares de reprodução no espaço social da grande Córdoba ${ }^{1}$, no contexto das dinâmicas socioeconômicas recentes da Argentina no período entre 2003 e $2013^{2}$. Neste projeto, indaga-se sobre um amplo espectro de práticas, incluindo estratégias profissionais, educativas, habitacionais e de consumo cultural. Esse processo incluiu uma etapa preliminar de reconstrução do espaço social das classes com base na perspectiva teórica de Bourdieu (1984), utilizando como fonte principal as informações provenientes do Sistema Estatístico Nacional argentino, especialmente da Encuesta Permanente de Hogares (EPH - Levantamento Permanente de Lares)33. O propósito dessa primeira aproximação foi o de construir a estrutura objetiva de possibilidades a partir da disposição de uma determinada estrutura e volume de capital para as diferentes famílias do espaço, posicionadas em diferentes classes e frações de classe.

A presente análise refere-se à segunda etapa de índole qualitativa. Quanto às estratégias profissionais especificamente, realizamos o trabalho de campo centrado na dinâmica da vida profissional de jovens de classes populares. Foram realizadas mais de cinquenta entrevistas a jovens, agentes estatais da área de emprego, docentes e representantes comunitários de bairros; observações em empresas, agências de emprego e escolas para jovens e adultos localizadas em bairros populares da grande Córdoba; além da análise documental de relatórios e materiais de formação referentes a políticas de emprego e à problemática da empregabilidade juvenil.

1. O Instituto Nacional de Estatísticas e Censos (Indec) considera "grande Córdoba" a conturbação da cidade de Córdoba (Argentina) com um punhado de localidades do departamento Colón, localizadas ao norte desta cidade. Compreende a cidade de Córdoba, capital da província, La Calera, Villa Allende, Río Ceballos, Unquillo, Salsipuedes, Mendiolaza, Saldán, La Granja, Agua de Oro, El Manzano e Guiñazú Norte. De acordo com o Censo 2010, a grande Córdoba conta com 1.412.182 habitantes (1.368.301, em 2001) em uma superfície de 21 mil quilômetros quadrados, o que a torna a segunda aglomeração urbana da Argentina em termos de população e superfície.

2. O projeto, radicado no Centro de Pesquisas da Faculdade de Filosofia e Humanidades da Universidade Nacional de Córdoba, intitula-se "Las clases y su reproducción en el espacio social cordobés (20032013)" e é financiado pela SECyT (Secretaria de Ciência e Tecnologia) da Universidade Nacional de Córdoba e dirigido por Alicia B. Gutiérrez e Héctor Mansilla.

3. A Encuesta Permanente de Hogares (Levantamento Permanente de Lares) é um programa nacional cujo propósito é fazer um levantamento sistemático e permanente dos dados referentes às características demográficas e socioeconômicas fundamentais da população e vinculadas à força de trabalho. Esse levantamento é realizado trimestralmente e tem cobertura nacional, abarcando os maiores centros urbanos da Argentina, aglomerados onde habita 70\% da população urbana. 
Com o objetivo de analisar as estratégias de gestão de recursos no âmbito do trabalho, começaremos reconstruindo a evolução teórica do diagnóstico sobre o processo de modernização como um desenvolvimento que desemboca na constituição de um mundo dividido em esferas. Para isso, retomaremos a contribuição específica de Max Weber sobre a formação do capitalismo moderno como um processo de racionalização e formação de "esferas de valor". A partir do estabelecimento desse acervo teórico clássico, proporemos algumas ferramentas conceituais para a articulação de explicações sobre a ordem interacional-configuracional da vida profissional, embora vinculadas à dimensão estrutural das relações entre as classes sociais. Para isso, recuperaremos especificamente os desenvolvimentos teórico-metodológicos de Florence Weber, sua proposta de etnografia multi-integrativa e sua noção de cenas sociais, inserindo-os na conceptualização bourdieusiana de espaço social (Bourdieu, 1984).

\section{Esferas, cenas e homologias: entre as estruturas e as interações}

\section{0 mundo em esferas: o relato sociológico da modernização}

A sociologia produziu uma série de diagnósticos sobre a modernidade, entre os quais o de Weber, que constitui sua versão consagrada. Sua caracterização do processo de modernização como eixo de análise (crítica) do processo de evolução da sociedade ocidental entre o século XIX e o XX nos servirá para estabelecer um acervo disciplinar comum do qual partem visóes de um mundo separado em esferas relativamente independentes e autorreguladas.

O primeiro elemento do diagnóstico consiste na crescente especialização, funcional e de funcionários, que encerra a totalidade da existência e que explica, entre outros, o surgimento do próprio Estado moderno e do tipo específico de quadros administrativos (burocracia moderna) que lhe correspondem (M. Weber, [1905] 2006, p. 7). Essa análise não está circunscrita necessariamente ao esquema e à perspectiva weberiana. Uma leitura homóloga leva Durkheim a recorrer à diferenciação funcional impulsada pela "economia" como elemento explicativo fundamental da passagem das sociedades de solidariedade mecânica para as de solidariedade orgânica (Durkheim, [1893] 1985, p. 256). Combinando as duas vertentes teóricas (a durkheimiana e a weberiana), Habermas relata a mesma passagem como uma transformação dos mecanismos de integração social, a partir de um acordo normativo básico generalizado, em conexões sistêmicas de âmbitos de ação funcionalmente especificados (Habermas, [1981] 1990, p. 163).

O segundo elemento que caracteriza a modernidade é a fundação do capitalismo em uma separação medular entre o espaço doméstico (lar) e o espaço de trabalho- 
-industrial (empresa). Se o capitalismo está igualmente caracterizado, em Weber, pela organização racional-capitalista do trabalho formalmente livre, por um lado, e pela contabilidade racional e a separação jurídico-patrimonial, pelo outro, os dois elementos baseiam-se na primeira separação. Isso também está enraizado no legado da sociologia clássica. Marx, por exemplo, narra a passagem do modo de produção feudal ao capitalista como um progressivo desembaraço da exploração puramente econômica com respeito à dominação pessoal. Embora o autor reconheça essa separação como "aparência” (ideológica), afirma-a como uma aparência necessária para sua transformação (Marx, [1844] 2004, p. 99). Em outro contexto de indagação, Dias Duarte (1994, 1995, 2004) e Semán (2006, 2007) tratam da separação dos mundos físico e moral da pessoa por parte da ideologia individualista moderna e da inadequação do modelo de pessoa próprio das classes populares a esse ideal hegemônico.

Algo relevante na versão especificamente weberiana da divisão é a constituição do espaço doméstico como um campo de competência especificamente familiar, âmbito por excelência de negociação pessoa a pessoa e de repressão do espírito de cálculo (Lenoir, 1993, p. 77), espaço privilegiado da "economia dos cuidados" (Bourdieu, [1979] 1988) e do desinteresse, em oposição à esfera econômica, cuja tipologia ideal é associada a uma racionalidade de tipo instrumental e produtivista.

Por último, a modernidade é vista por Weber, e depois por Lukács ([1923] 1985), como um progressivo processo de racionalização, uma imposição da racionalidade capitalista (como orientação prática para a vida do indivíduo), da disciplina laboral e do crescimento da produtividade no trabalho (Corrigan e Sayer, 2007) a partir da construção de uma esfera de trabalho fortemente tecnificada, regulada pela noção de origem protestante - de "profissão" (M. Weber, 2006, pp. 67-68) e, por extensão, por um processo de autocontrole e ascetismo na totalidade da vida humana. Nesse ponto, Weber mostra as “afinidades eletivas" entre a ética protestante e o espírito do capitalismo ou entre a racionalização religiosa (rejeição, como superstição, da busca de meios mágicos de salvação) e o desencantamento do mundo (racionalização, planificação e metodização moral da vida e das práticas mundanas).

É a partir desse processo, assim diagnosticado, que podemos falar, seguindo Brubaker, de esferas de valor no pensamento weberiano, como reinos de atividade diferenciados, resultados emergentes do processo de racionalização moderno ocidental, ou seja, da consciência crescente de autonomia normativa, axiológica e causal dessas esferas (Brubaker, 1984). Embora essas diferentes esferas de valor tenham uma inerente consistência racional típico-ideal em seu interior (Idem), entre si cruzam-se e interpenetram-se em um conflito objetivo, resultado de "processos de racionalização divergentes” (Idem, p. 78). Esses conflitos - estruturalmente irreconciliáveis sempre seriam resolvidos em "orientações individuais de valor"; na medida em que 
é impossível uma prevalência racional, a escolha decide, justamente, entre "critérios de racionalidade" (Idem, p. 87).

Esse conflito de caráter objetivo e inerente à divisão do mundo em esferas leva a questionar, no pensamento weberiano, a própria possibilidade de uma "vida racional". O problema é que, com todo seu potencial crítico, deixa as articulações entre esferas à mercê de escolhas individuais, sem ferramentas conceituais para uma análise que pretenda articular, teórica e metodologicamente, aproximações a essas esferas como espaços interacionais, com a dimensão estrutural, como espaço social das classes.

\section{Das configurações às cenas sociais}

Nos termos da conceitualização de Elias ([1970] 1982), de individuos interdependentes que se enfrentam com margens de ação limitadas, entendemos que o espaço social, ou o espaço das classes, pode ser considerado (também) como um entrelaçado de múltiplas interdependências que vinculam os agentes. Desse modo, propomos uma abordagem das esferas da vida social que articula as dimensões estrutural e interacional e que estabelece seu lócus de estudo ao passar da noção mais ampla de "configuração" (Idem) para a mais precisa de "cena social” (F. Weber, [1989] 2009; 2001; 2002).

De fato, para Elias ([1970] 1982), o tecido social está permeado por numerosos modos de inter-relação que se entrecruzam, "configurações" que consistem em formas específicas de interdependência que ligam uns indivíduos a outros e que se diferenciam pela longitude e complexidade das diferentes cadeias de inter-relações.

Como aponta Corcuff, as dependências recíprocas não implicam necessariamente relações iguais e equilibradas, e, de fato, em suas análises empíricas, Elias demonstra que, em geral, as configurações se caracterizam pela desigualdade, dominação e poder. Mas, aqui, o poder não é essência nem substância: é uma característica associada a essas dependências recíprocas, que fazem que uns indivíduos dependam de outros e, assim, vejam limitadas suas capacidades de escolha e ação (Corcuff, 2013). Apelando à metáfora do jogo, sua perspectiva teórica considera que as diferentes jogadas dos indivíduos estão imbricadas, e isso gera dinâmicas que fogem à vontade e aos desígnios dos jogadores envolvidos: "A interdependência entre as diferentes posições gera processos regulares que se impõem a cada jogador como processos impessoais, ao exercer no conjunto do entrelaçado uma coação sobre o comportamento de cada um dos atores" (Martín Criado, 2008, p. 19).

No entanto, não pretendemos identificar essa noção de "configuração" com a bourdieusiana de campo ou de espaço social ${ }^{4}$ - como sugere Heinich (1999) -,

4. Espaço social e campo, para Bourdieu, são duas construçôes diferentes para explicar as "estruturas obje- 
mas propomos uma maneira de combiná-las teórica e metodologicamente, como preconiza Martín Criado (2008), especificando âmbitos mais apropriados para suas utilizações analíticas. Nessa intenção de gerar ferramentas adequadas para nossos objetos de estudo, apelamos para a proposta de Florence Weber para explicar a complexa gama de interações suscetíveis de serem observadas nas diferentes esferas da vida e suas interpenetrações.

Partindo de uma etnografia multi-integrativa, "que pretende capturar totalidades socioculturais com base em observações localizadas" (F. Weber, 2001, p. 475), Florence Weber supóe o âmbito do trabalho de campo como uma cadeia de interdependências, no sentido em que Elias o interpreta, e como uma espécie de universalização da análise interacional de Bateson.

Em seu estudo sobre Montbard (F. Weber, [1989] 2009), ela analisa o "trabalho paralelo" (travail à côté) e propõe apreender diferentes "âmbitos de atividades" para classificar as diversas ocupações dos operários fora da fábrica, considerando-as como um continuum entre o prazer de estar ativo e o benefício econômico ou simbólico.

O trabalho paralelo está ligado a uma área específica de relações sociais, uma cena social, definida como "subconjunto de relações orientadas por uma prática no conjunto das relações tecidas por um indivíduo" (Idem, p. 193). Esse conceito permite a Weber abordar um conjunto de domínios da realidade social, construindo diferentes situações de interação, com seus códigos particulares (de cumprimentos, cortesia, intercâmbio), sem abandonar a noção mais estrutural de "campo", embora com a precaução de não autonomizar prematuramente um domínio sob o suposto funcionamento de um "mercado" ou um "campo de forças". Desse modo, Weber reconstrói uma série de homologias possíveis (entre a cena residencial, parental, esportiva e profissional) em um contexto espacial de relativa fusão das cenas profissional e residencial (Assusa, 2014).

Em um trabalho posterior sobre horticultores aficionados, Florence Weber (2002) retoma essa ideia e demonstra que existe uma pluralidade de cenas sociais que se correspondem com uma série de racionalidades práticas: nessas cenas, os indivíduos interagem e suas ações adquirem significado. Além disso, ao analisar o modo em que se configura o ritual das diversas transações, mostra que o consumidor racional (no sentido da teoria utilitarista) não tem que depender de nenhum cálculo explícito, já que o éthos ascético encontra-se inscrito nas rotinas do corpo. Tal como aponta Ténédos (2006), a contribuição fundamental de Florence Weber foi revelar 
as insuficiências da modelização do cálculo econômico e sugerir que cada cena social privilegia uma maneira particular de medir e de contar.

Esse modo de conceitualizar permite a Weber confrontar uma série de aspectos (ocupações ativas/ocupações passivas; gosto/necessidade; racionalidade econômica/ racionalidade prática). Para os propósitos do nosso trabalho, sistematizamos o seguinte:

- Primeiro, “a 'cena social' é o universo de referência e socialização no qual as interações adquirem significado para os participantes” (F. Weber, 2001, p. 485).

- Não se trata necessariamente de um espaço de copresença física, mas de um espaço que contém uma série de lugares relacionados por uma definição comum da situação e por um conhecimento mútuo dos participantes.

- Essas cenas sociais não envolvem indivíduos que jogam o jogo abstrato do mercado, mas pessoas definidas por suas relações, suas coisas e seus territórios. Além disso, considerando as precauções ligadas à “ilusão biográfica” (Bourdieu, 1986), afirma-se que "a pessoa aparece como ponto de intersecção entre muitas cenas de interconhecimento e a trajetória pessoal aparece como uma sucessão de pontos de intersecção" (F. Weber, 2001, p. 489).

- Consequentemente, propóe-se uma etnografia que enfatize a realidade de cadeias de conhecimento mútuo e interdependência 5 .

Contudo, neste estudo, identificamos e reconstruímos essas cenas sociais com base na análise da estrutura do espaço social cordobês, como espaço de similaridades e diferenças derivadas da distribuição desigual dos recursos objetivos (especialmente capital econômico e capital cultural sob a forma de capital escolar) que posicionam seus protagonistas de maneira desigual.

Dessa forma, descrevemos uma série de situações em âmbitos de trabalho em termos de cenas sociais e interpretamos as lógicas práticas postas em jogo nessas situações, como a produção de uma série de homologias possíveis para a gestão dos recursos no contexto de interaçóes laborais, levando em conta que seus limites e possibilidades se encontram definidos nas estruturas objetivas das relações de classe.

A posição na estrutura do espaço social cordobês: a classe baixa dominada

Consideramos o espaço social no sentido de Bourdieu (1986), como uma construção teórica ("no papel”), uma ferramenta analítica que, levando em conta

5. Florence Weber $(2001,2002)$ aponta explicitamente esforços analíticos similares em outros autores contemporâneos como Lahire (1998) e Zelizer (2000). 
simultaneamente um conjunto de variáveis relativas a recursos econômicos e culturais e apelando a métodos específicos, permite caracterizar as diferentes posições (e suas relações) de nossas unidades de análise (famílias) e identificar classes e frações de classe. Procedendo desse modo, não pretendemos abordar as classes sociais predefinidas, e sim reconstruir o sistema de relações que elas formam, para identificar nele conjuntos de agentes que ocupam posições semelhantes, com condições de existência homogêneas.

Associando uma análise de correspondências múltiplas $(\mathrm{ACM})^{6} \mathrm{com}$ o método de classificação hierárquica ascendente $(\mathrm{CHA})$, construímos o espaço social cordobês e identificamos quatro grandes classes com suas respectivas frações (Gutiérrez e Mansilla, 2015).

Levando em conta a estrutura correspondente ao terceiro trimestre de 2011, selecionamos jovens pertencentes ao que dominamos classe baixa dominada (1/4), composta por cerca de $20 \%$ da amostra tomada pela EPH, de 532 residências ${ }^{7}$. As famílias que compõem esta classe apresentam condições de existência que se caracterizam por seu baixo volume global de capital, com uma estrutura patrimonial associada a baixa renda: renda per capita familiar (RPCF), renda total do referencial da família (RF), renda pela ocupação principal do RF e renda total familiar localizadas no primeiro decil. Ao mesmo tempo, estão associadas, quanto à ocupação de seu RF, com falta de qualificação profissional, serviço doméstico, atividades por conta própria e ligadas à construção, com certa precariedade no trabalho, pouco tempo de serviço, trabalho desenvolvido

6. Como variáveis ativas da ACM, selecionamos propriedades correspondentes ao lar e a seu referencial (levando em conta o capital econômico e o capital cultural). Assim, com relação à disponibilidade de recursos econômicos do lar, levou-se em conta a "renda per capita familiar" (RPCF, considerada em decis do aglomerado), ao mesmo tempo que foram selecionadas certas características do referencial da família, tais como sexo, idade, situação conjugal, nível educativo (capital escolar como subespécie do capital cultural) e outras vinculadas à sua inclusão nas relações de produção, em particular, hierarquia e qualificação ocupacional e, por fim, sua renda total individual.

7. O primeiro fator do espaço social contrasta as famílias mais bem providas em termos de volume global de capital com aquelas com menor provisão de recursos. Expressando 7,2\% da inércia total e conformada principalmente pelas contribuições da renda per capita familiar (RPCF), a qualificação ocupacional do referencial da família (RF), sua renda total e seu nível de instrução, este eixo diferencia, na região superior do plano, as posições sociais com maior volume global de capital, ou seja, o máximo de recursos econômicos - expresso na categoria do $10^{\circ}$ decil na RPCF - e alto volume de recursos culturais - indicado pelo nível de instrução formal alcançado pelo RF, que chega a estudos universitários completos. A essas propriedades, somam-se outros indicadores do volume patrimonial, como a qualificação e a posição hierárquica maior da ocupação profissional do RF (profissional formado e cargos de direção). $\mathrm{Na}$ região inferior do espaço, estão localizadas as posições que apresentam menor volume global de recursos, tanto econômicos quanto culturais; a inclusão no primeiro decil da RPCF e os estudos primários incompletos como máximo nível de instrução formal alcançado pelo RF são alguns dos indicadores que expressam mais claramente sua situação na região dominada do espaço social. O segundo fator distingue as regiões médias do espaço social, que se diferenciam entre si pelo volume global de capital possuído. 
em pequenos estabelecimentos, do âmbito privado ou como trabalhador autônomo, e com falta de cobertura médica. O capital escolar do RF vai de nível primário incompleto ao primário completo. Quanto às características dos lares e domicílios desta classe, observamos uma associação com RF femininos, idosos, superlotação e condição de "ocupante" da moradia como regime de posse. Por último, podemos afirmar que esta classe de famílias se associa ao recebimento de subsídios e ajuda material.

No entanto, se o baixo volume de recursos permitiu recortar esse grupo como classe, existem, no seu interior, diferenças secundárias que permitem distinguir duas frações com diferentes estruturas patrimoniais. Embora os dois grupos possuam baixo volume global de capital expresso em renda dentro dos primeiros decis e RF cujos estudos não superam o nível primário, as frações mostram diferenças com respeito ao sexo do RF e ao tipo de inclusão no mercado de trabalho que este consegue. Assim, os fatores constitutivos da classe encontram-se - em cada fração - mediados pelas determinações impostas pelo gênero. Desse modo, uma primeira fração da classe, que inclui $10 \%$ do total dos lares, agrupa famílias que possuem altas porcentagens (quase 80\%) de RF feminino: trata-se de mulheres separadas ou viúvas, sem qualificação profissional e que desempenham serviço doméstico. Por outro lado, uma fração de aproximadamente $12 \%$ de lares possui, na sua maioria, um RF masculino, com ocupações vinculadas à construção e ao trabalho por conta própria, com qualificação profissional operativa e que constitui lares numerosos.

\section{A submissão estratégica: formas de interação doméstica e no trabalho}

"Abaixar a cabeça" é uma qualidade que parece ser fundamental para manter o trabalho nessas relações estruturais. Diante da falta de outras credenciais, como qualificação, formação profissional certificada, ofício ou experiência, a construção de uma imagem de "trabalhador submisso" pode funcionar como eficaz substituto, fundamentalmente em atividades (aparentemente) sem muitas exigências ou complexidade técnica.

Inês utilizou esta expressão ao criticar uma de suas conhecidas. Segundo nos contava, sua amiga era "muito geniosa”.

Ao ser indagada se opinava que Jéssica (uma moça que conhecia de um curso de capacitação profissional e era relativamente próxima) podia conseguir emprego. Disse que sim, porque se expressava bem, mas que era muito geniosa e estava sempre com a cara fechada. Quando perguntamos sobre seu próprio caráter, disse que ela também tinha temperamento forte, mas que sabia "abaixar a cabeça" e engolir as palavras (Nota de campo, set. 2012). 
Ela tinha 22 anos e um filho de 4 anos. Antes que seu filho aprendesse a andar, teve que aceitar um trabalho para dormir no emprego. Sua tarefa era entregar "marmitas" de um estabelecimento que oferecia refeições no bairro. $\mathrm{O}$ serviço oferecido pelo estabelecimento era a entrega de refeições na hora do almoço para pessoas que trabalhavam nas imediações (especialmente nas obras de construção). Por uma questão de imagem, seus patróes não permitiam que ela levasse o bebê consigo durante as entregas porque "passava má impressão", além das dificuldades causadas pela mobilidade com seu filho e as marmitas. Por isso, Inês deveria deixar o bebê aos cuidados de seus patrôes enquanto tomava e entregava os pedidos. Quando regressava, encontrava o filho "todo cuspido" ou maltratado fisicamente pelas filhas dos donos do estabelecimento.

Se grande parte das competências postas em jogo, nesse e em trabalhos anteriores da sua trajetória individual e familiar, estavam diretamente relacionadas com o espaço do lar (cuidado de crianças, limpeza, cozinha etc.), os elementos vinculados a esse mesmo espaço serviam-lhe de critérios de valor moral para avaliar a ilegitimidade da atitude de seus patrões. $\mathrm{O}$ espaço do lar e o do trabalho, em sua experiência, não estavam separados. De fato, seu filho morava, junto com ela, no seu próprio espaço de trabalho. E o cuidado, ao mesmo tempo, laboral e familiar, foi o que determinou a maneira em que essa relação de trabalho seria interrompida, ocasionando que Inês voltasse a morar na casa de sua mãe.

A questão é que, um dia, eu ia saindo, eu tinha um quartinho no quintal. Um dia, vou saindo e vejo que a menina levava o José [seu filho], tinha uma escada de cimento, no quintal. Lá de cima, a moleca empurrou o José. E o José se cansou de chorar, então eu levei ele no hospital, para tirarem umas radiografias da cabeça dele, mas não tinha nada. Daí, então, eu falei com eles, disse que não queria mais, que ia embora, bom, sei lá, e fui embora (Inês, 22 anos, beneficiária de um programa de emprego estatal).

Natália, que tinha feito um curso junto com Inês, nos contava em uma conversa que, embora fossem "do mesmo signo" (faziam aniversário em dezembro), no fundo eram muito diferentes. Fazia referência à indecisão de Inês, a que "não é muito positiva": "você vê que ela é meio rebelde... para mim, é como se ela quisesse sempre aparecer". Do ponto de vista de Natália, "aparecer" era um modo ilegítimo de buscar reconhecimento no trabalho. Uma modalidade alheia à lógica laboral. Ao narrar um conflito com a nova encarregada do salão onde Natália trabalha (alguém "parecido com Inês"), falava da "falta de critério" com a qual essa pessoa dava ordens, querendo "sobressair", sem considerar o que era melhor para o grupo de trabalho.

8. Expressão coloquial para se referir àquele que busca sobressair-se exageradamente. 
Natália trabalha em um salão de festas de aniversário para crianças. Conta, com relação a uma encarregada que esteve um dia, que já entrou gritando, mandava-a fazer algo e, logo, dizia: "Não, isso não se faz assim". "A mulher teve que aguentar umas caras feias, minha e da minha colega também". Natália afirmava que a encarregada "agia mal", porque a deixava de mau humor e ela (Natália) tinha que estar ali, como animadora, com crianças durante três horas (Nota de campo, maio 2012).

Segundo sua própria lógica, é preciso saber distinguir espaços, momentos etc. Da mesma idade que Inês e com uma filha de três anos, Natália desempenhava tarefas como animadora em um salão de festas infantis, atividade na qual possuía vasta experiência e que realizava desde os doze anos. Embora as competências postas em jogo em seu trabalho proviessem do mesmo acervo doméstico que as de Inês (vinculadas ao que denominamos economia dos cuidados), suas classificações distinguiam claramente os códigos de interação do espaço doméstico e os do espaço de trabalho, sujeito, este último, a relações formalizadas, mais distantes, em que se aplicava uma férrea atitude de "perfil baixo".

Inês, primeira defensora da necessidade de abaixar (estrategicamente) a cabeça e evitar os conflitos no âmbito do trabalho, encontrava um limite para essa atitude na segurança de sua própria família e, portanto, no questionamento de suas próprias capacidades de cuidado: até esse momento, o principal recurso posto em jogo em sua vida profissional. De certa forma, sua diferenciação encontrava lógica na defesa da validez e legitimidade daquele, seu principal capital.

A partir dessas trajetórias, que, de certo modo, podem ser consideradas típicas na classe baixa dominada do espaço social cordobês, construímos duas modalidades de homologias entre o espaço doméstico e o espaço de trabalho: a de Natália, que implica uma translação exclusiva de competências (de cuidado), que produz, porém, descontinuidade nos códigos de interação legítimos para cada uma dessas esferas, e a de Inês, que constrói, de forma indiferenciada, certos capitais de cuidado tanto para o lar quanto para o trabalho e que unifica os critérios de valor moral entre ambas as cenas. Nesse sentido, podemos distinguir, nessas posiçóes sociais, uma homologia de capitais (competência de cuidado) e uma homologia de condições de valorização simbólica dos capitais (o cuidado como critério de legitimidade).

As entrevistas com Leandro sempre transcorreram na sua própria casa e, por isso, contavam, quase sempre, com a participação ativa de sua irmã mais velha e de sua própria mãe. Ele encarnava uma reputação e se autoidentificava na imagem de "bom 
rapaz". Era muito apreciado pelas professoras da escola primária, bem como pelos professores dos cursos de formação profissional que realizou. Seus familiares contam que possui o hábito da pontualidade. É sempre o primeiro a chegar.

Quando mencionei que Leandro sempre era muito pontual, a mãe contou rindo que a zeladora da escola primária de Leandro dizia que ele a ajudava a acender as luzes, porque era sempre o primeiro a chegar (Nota de campo, jun. 2012).

Ele fala baixinho e de maneira pausada. É de compleição miúda e, ainda assim, realizou durante muito tempo as tarefas mais pesadas no trabalho de construção, como ajudante de pedreiro. Sua madre explica, no entanto, que ele não tinha "corpo" para "a obra" Também conta que, assim como se destacava por ser um bom menino na escola primária, no colegial, passou a ter muitos problemas, embora nunca de comportamento. Segundo relata, a escola era difícil para ele porque Leandro tinha problemas de aprendizado:

E a diretora me dizia, faça ele estudar, porque vai ser difícil... conseguir trabalho, você sabe como são as pessoas, como discriminam. Faça ele estudar. E deixaram ele ficar durante três anos, mas depois ele disse: não, vou largar, mãe. Então ele largou... era muito difícil para ele. Porque o primário ele terminou aos quinze anos. Como ele era bonzinho e tinha bom comportamento, a professora deixou que ele terminasse o primário na (escola) Vicente Forestieri (Maria, 59 anos, mãe de Leandro).

Ao contrário de outros jovens que entrevistamos, Leandro não destacava suas próprias habilidades técnicas. Isso se combinava com uma carência ainda mais acentuada de credenciais educativas. Por tudo isso, sua irmã recomendava-lhe sempre a mesma coisa: "abaixe a cabeça e não crie problema... chegue sempre cedo e você vai se sair bem". Lorena se gabava do controle que exercia sobre seu irmão: "espantei todos os seus amigos e fiz isso para ele terminar o quartinho", aposento onde, fazia alguns meses, dormiam Leandro e sua mãe. Segundo ela, afastá-lo da "rua" é o que lhe permitiria crescer, ter suas coisas e progredir.

O emprego de Leandro, naquele momento, havia sido obtido por intermédio de sua irmã na empresa de transporte onde trabalhava. Leandro conta que, na primeira semana de trabalho, seu superior "se fazia de besta" na hora de dar seu horário de descanso e deixava-o limpando as unidades de transporte, enquanto o resto dos empregados tomava o recreio para o café da manhã e o lanche sem nenhum problema.

9. Termo nativo para fazer referência ao trabalho na construção. 
Muito incomodado pela situação, ele, no entanto, enfatizava: “eu não digo nada... engulo tudo".

Sua irmã sabe que a recomendação (como modo de inclusão no trabalho) torna instável a posição de Leandro, ao mesmo tempo que põe em risco seu próprio prestígio dentro da empresa. Lorena conta que conseguiu o emprego para o seu irmão porque é "amiga" de um dos chefes e "se faz de amiga" de uma mulher dos escalóes intermédios da empresa. Nesse sentido, o capital social (Lomnitz, 1978; Gutiérrez, 2004, 2011) investido possibilita a inclusão laboral de Leandro, diante da ausência de outras credenciais, mas também limita suas reações no trabalho (a possibilidade de reclamar diante de situações que considera injustas). Envolve um compromisso (com a empresa, por parte de Lorena, e com sua irmã, por parte de Leandro), devido ao risco que corre o capital social familiar, apostado nessa estratégia ${ }^{10}$.

Respeito: a fala, a aprendizagem e a honestidade

"Essa é uma das minhas características, e sempre me trouxe problema... eu digo o que penso". Luís parece mais velho do que realmente é. Veste-se sempre com jeans de corte reto, pulôver e tênis brancos. Nunca está muito agasalhado. Tem as mãos fortes, de dedos curtos. Ao falar, habitualmente, olha para as próprias mãos, com o cenho franzido, evitando o olhar dos interlocutores.

Ao estagiar em uma fábrica de bicicletas, teve "problemas" com um de seus colegas. Na linha de montagem, este último "se esquecia" ou não chegava a cumprir sua tarefa a tempo, atrasando o trabalho de Luís. Começaram a surgir conflitos e acusações cruzadas sobre as responsabilidades e a carga de trabalho que cada um devia assumir. "Eu o encarei", diz Luís. O chefe da área interveio, falou com os dois separadamente e depois com os dois juntos: "Ficou tudo bem".

Assim, cada um por seu lado. E um não mexia com o outro... e a coisa é que, depois, não ficamos aí no emprego, porque estávamos em prazo de experiência e éramos quatro caras e, dos quatro, só ficavam dois... e, então, o chefe não viu que a gente, eu e o Cristian, ele não viu... que a gente trabalhava bem. Não éramos... (Luís, 24 anos, beneficiário de um programa de emprego estatal).

10. O risco não inclui exclusivamente seu patrimônio de capital social. Segundo nos contou sua mãe, depois da demissão de Leandro da empresa, sua irmã tinha muito medo devido às dívidas que tinham na casa, principalmente as relacionadas com os acabamentos (ainda estavam pagando o portão da frente), e a demissão do irmão havia provocado certas dúvidas sobre sua própria estabilidade no trabalho. Por outro lado, embora o marido de Lorena tivesse trabalho na obra, devido ao clima naquela semana, só havia podido trabalhar por três dias e isso influenciaria seu salário. 
No momento da seleção dos estagiários como empregados permanentes da empresa, os superiores consideraram que as "maneiras" de Luís não se encaixavam nos códigos de interação que a empresa pretendia para os seus trabalhadores. Quando a empresa comunicou sua decisão aos responsáveis do programa de emprego do qual ele participava, argumentaram que o jovem cumpria todas as tarefas na sua dimensão técnica, que era ativo, rápido e capaz, mas que não podia trabalhar em grupo. "Cada um por seu lado", dizia Luís, enunciando a resolução positiva do conflito, segundo sua própria avaliação.

A honestidade aparece como um princípio-chave na avaliação moral das relações de trabalho por parte desses jovens. Dizer o que pensa, falar a verdade, "não fazer as coisas pelas costas", "não ser falso" são formas diversas que eles usam para fazer referência a uma maneira de afirmar simbolicamente sua posição, de buscar construir uma reputação e uma identidade no trabalho.

Em seu estudo sobre as fronteiras morais na classe trabalhadora, Michèle Lamont estabelece uma relação entre o valor da honestidade e a integridade pessoal:

Para eles, a confiança e a previsibilidade não se conseguem evitando os conflitos, seguindo a orientação da equipe e pela flexibilidade, mas pela simplicidade [...]. Os trabalhadores, além disso, valorizam a integridade pessoal, ou seja, a defesa dos próprios princípios, ainda na adversidade. Este traço nem sempre é compatível com a prevenção de conflitos, a flexibilidade e a orientação da equipe, elogiadas pelos profissionais e chefes. Ao contrário dos profissionais com mais formação, eles colocam a sinceridade por cima da flexibilidade, talvez como uma forma de resistência da classe trabalhadora (Lamont, 2000, pp. 36-37).

Em sua etnografia sobre a economia clandestina no Harlem, Bourgois narra a experiência de um de seus informantes, similar à de Luís. A estranheza com que este habitante de El Barrio via o sentido comum do trabalho administrativo é captada no texto como um choque entre a "cultura da rua" e a "cultura yuppie" (Bourgois, [2001] 2010, p. 178); quando os homens dos setores populares entravam nos ambientes de trabalho do setor de serviços ou relativamente formais, seu comportamento manifestava uma ancoragem em formas culturais que reconheciam a rudeza e a resistência como recursos valiosos no mundo da fábrica e ainda valorizados nas interações no bairro. Reassentados em cenas de trabalho com certo grau de formalização, em que a coordenação e as formas de interação adquirem particular relevância, esses recursos, capitalizáveis na vida do bairro popular, tornam-se empecilhos e são percebidos como incompetências para a comunicação (a honestidade aparece aqui como inflexibilidade) por agentes que ocupam posições de maior hierarquia (encarregados, chefes) e que incorporaram disposições (a valorizar positivamente o discurso da flexibilidade e da 
atitude positiva diante do trabalho dos profissionais de recursos humanos) fundadas em outras condições objetivas, marcadas pela maior disponibilidade de capitais econômicos e culturais.

Luciano vive em um bairro pobre, caracterizado por ser a sede de uma das cooperativas de catadores de papel e de papelão mais importantes da cidade. Nesse lugar, há pelo menos uma década, milita um grupo de jovens universitários de uma organização política de esquerda que atua em diferentes espaços comunitários. Luciano conheceu esse grupo quando tinha aproximadamente 16 anos. Assume essa experiência como um ponto de viragem em sua vida: "Antes eu queria ser da polícia”.

2004, 2005... E, então, eu dizia, que matem todos esses grevistas de merda, eu via os caras da polícia quando entravam em ação e atiravam; daí, eu dizia, tomara que matem todos [exagerando]. Mas era pensamento de moleque [...] de cabeça vazia, porque nessa época eu não tinha ideia de política, não conversava sobre essas coisas com ninguém. E, quando voltei para Córdoba, a primeira coisa que disse para a minha mãe foi: "Vou estudar, vou terminar o colegial e vou entrar para a polícia”. [...] Depois conheci os garotos e disse para a minha mãe: "Olha, não, não quero entrar para a polícia, na verdade, eu sou contra o que a polícia faz" [o entrevistador ri] e ela me diz: "Eh, por quê? "Porque os garotos são manifestantes, sei lá, eu gosto mais dessa onda... entende? Lutar por aqueles que estão por baixo, lutar por você, lutar pelo vizinho, por quem está do lado e por mim também [...]”. E ela me disse: “Não, esses esquerdistas te viraram a cabeça...”, porque a minha mãe é radical. E ela me diz: “Esses esquerdistas viraram a sua cabeça, você não sabe o que diz... você já vai ver”. E agora já faz seis anos que estou militando (Luciano, 23 anos, beneficiário de um programa de emprego estatal).

Sua experiência no movimento, e principalmente nos momentos de assembleias, deu-lhe, segundo sua própria descrição, "ferramentas" para se desenvolver e potencializar seus escassos recursos em diferentes âmbitos, ou seja, a capacidade de expor suas razões, negociar e ser atendido.

Me fez ser quem eu sou agora. Mudou minha vida em muitas coisas. Mudou minha vida, me ensinaram... a militância me ensinou a me defender, assim, para o futuro [...] Quer dizer, me ensinou a me defender no trabalho, assim... quando a polícia te parava... antes, se a polícia me parava, eu ficava com muito medo e começava a chorar, dizendo: "eu não fiz nada”. Agora a polícia me para e eu enfrento [...] faz uns dois anos já, me levaram preso e a primeira coisa que eu fiz foi enfrentá-los todo o tempo, assim para mostrar que eu não tinha medo deles [...] [Eles percebem] não que você foi preparado, mas que você se informou bastante, sobre a polícia, sobre como se defender, como falar com eles, o que dizer [...]. E eles ficavam com muito receio, muito medo. [...] Porque o que eu dizia era, não, não, você não pode me levar 
assim, não pode me bater, porque eu vou te denunciar para os [defensores dos] direitos humanos... e são coisas que não muita gente sabe (Luciano, 23 anos, beneficiário de um programa de emprego estatal).

O relato sobre as detenções aparece, no seu depoimento, em paralelo com conflitos que Luciano teve dentro da assembleia do movimento: "avacalharam comigo", diz. Mas também com conflitos no seu último trabalho. Sobre isso, Luciano destaca a maneira em que "soube" resolver o problema com seu colega de trabalho.

Conta que havia tido problemas com um "velho" que trabalhava no Correio Andreani, onde ele fazia um estágio. Diz que está "meio louco", que "avacalha" com todo mundo; quando o tratou mal, Luciano mandou-o "à merda". Depois, os colegas de trabalho falaram com Luciano e o aconselharam a se comunicar com o gerente. $\mathrm{O}$ gerente explicou que havia que o deixar em paz porque o homem estava prestes a se aposentar: "Faz vinte anos que ele está na empresa e não podem mandar ele embora" (Nota de campo, ago. 2012).

Sobre aquela ocasião e daí em diante, fala de suas reações em termos de argumentação e diálogo. Esse novo saber, desenvolvido pela presença assídua nas assembleias e pela convivência com jovens universitários, permitia-lhe enfrentar de outra maneira situações que lhe eram cotidianas. Um exemplo disso é seu relato sobre as detenções arbitrárias da polícia na via pública. Se antes mostrava temor, agora sabia que deveria defender-se e "enfrentar", atitude que, segundo ele, causava medo nos próprios agentes da polícia. Sua interpretação residia no fato de que os policiais se assustavam ao se encontrar com alguém que "sabia" o que estava dizendo e que "conhecia" o código de faltas ${ }^{11}$, questão que eles ignoravam por completo.

Sua passagem pelo movimento, a experiência das assembleias e, portanto, seu aprendizado sobre como expor ideias de maneira ordenada e fazer um uso intensivo da fala (uma espécie de capital militante, no sentido de Matonti e Poupeau, 20042005), valeram-lhe maior sensação de segurança e a capacidade de se defender na "rua" e também no "trabalho". A translação de formatos para a resistência ao maltrato em diferentes esferas sociais é possível na medida em que se homologam códigos vinculados fundamentalmente à forma de discurso. A fala e as competências linguísticas aparecem, ao mesmo tempo, como recursos escassos e muito valorizados para esses jovens ${ }^{12}$. Em termos estratégicos, suas referências para o discurso e seu uso

11. O código de faltas é um conjunto de leis que continua em vigor na província de Córdoba e que permite à polícia realizar prisões preventivas de pessoas, em geral, nas ruas baseando-se apenas em suposições [N. T.].

12. É muito comum que, em nosso trabalho de campo, sobretudo entre as mulheres, distinguissem as 
para a solução de conflitos em diferentes cenas sociais (e com diferentes resultados práticos) baseiam-se na adoção de disposições corporais dominantes na cena do trabalho. A diferença que Luciano traçou entre ele e os policiais, bem como entre ele e o colega de trabalho que "mexeu" com ele, funda-se menos em uma diferença política que em uma diferença cultural, de conhecimento, de saber e do medo ou da incapacidade que se associa com sua ausência.

Grande parte dos conflitos na cena de trabalho surge em termos de trato e de códigos de interação, seja nas relações entre pares ou com superiores. A partir disso, Alejandro diferenciava "estilos" de chefes.

Seus primeiros empregos (em uma loja de videogames e em uma oficina mecânica) apresentavam um componente "técnico" e foram obtidos por intermédio de conhecidos ou pelos contatos do seu pai. No segundo emprego, esteve dois anos e diz estar agradecido por tudo o que aprendeu e pela paciência do chefe ao corrigir seus erros, ensiná-lo e estabelecer limites, principalmente porque, nessa época, lembra ter feito "muita besteira". Essa experiência aparece como contraponto do seu atual chefe, que não diferencia entre "chamar a atenção" e "maltratar". Ele achou que tinha que responder a esse maltrato, depois de pedir a opinião dos pais, porque "a gente tem que se fazer respeitar" (Nota de campo, abr. 2012).

“Sempre com respeito", como ele pontua, citando sua mãe, falou com o superior e com representantes do programa de emprego dentro do qual fazia seu estágio para estabelecer acordos de interação nos quais não lhe faltassem ao "respeito", ou seja, que não se dirigissem a ele com palavras vulgares ou ofensivas ou levantando a voz e que lhe explicassem quantas vezes fosse necessário para que pudesse compreender suas tarefas: "Se eu estou aprendendo, eles não têm por que me tratar mal para me explicar as coisas".

Alejandro é um dos jovens com maior capital escolar em sua família de origem. Seu pai e sua mãe trabalham como enfermeiros no âmbito da saúde, sua mãe, em um hospital público e seu pai, em um privado; para esses cargos, contar com títulos superiores habilitantes é condição necessária. Além disso, a escola na qual Alejandro cursou o colegial é de orientação técnica (em eletricidade, primeiro, e eletrônica, depois), e seus conhecimentos técnicos foram fundamentais para sua trajetória de trabalho ${ }^{13}$. Nesse sentido, a estrutura patrimonial de seus recursos familiares dá certos indícios

pessoas pela forma de falar: "saber se expressar" faz com que alguém seja mais adequado para um posto de trabalho; "falar mal” faz referência não só a questões de dicção, mas também opera como sinédoque para a "educação" intelectual e moral geral de uma pessoa.

13. Uma de suas ocupações consiste em oferecer serviços de som em festas, para o qual ele mesmo armou seus equipamentos de som. 
sobre a lógica a partir da qual esta homologia é tecida: a validez da experiência de aprendizado que ele reclama no espaço de trabalho estabelece, sem subverter ou tensionar suas relações de força, alguns limites normativos na cena e nas formas possíveis de interação com aqueles que têm o controle do processo de trabalho (seus chefes ou superiores). Essa construção de limites normativos levaria os agentes que ocupam posições de maior hierarquia a cumprir determinadas normas de etiqueta com respeito ao "trato" e à "maneira de dirigir-se" a ele. Ao se fazer respeitar, Alejandro lutava para garantir e manter as condiçôes de valorização do capital cultural posto em jogo e por revestir simbolicamente a instanciação de sua própria posição nas interações laborais a partir de tal valorização.

\section{Conclusão}

A partir de um estudo geral sobre as estratégias familiares de reprodução no espaço social cordobês no contexto de suas dinâmicas recentes, centramos nossa atenção na reconstrução do que poderíamos chamar "estratégias de gestão de recursos" de jovens de classes populares, que denominamos classe baixa dominada em nossa construção do espaço social cordobês, ressaltando a resolução de conflitos nas cenas de trabalho nas quais esses jovens participam.

Após o reconhecimento do processo histórico e teórico que leva a considerar a vida social como um mundo dividido em âmbitos diferenciados de atividades relativamente autônomas, "esferas de valor" que resultam do processo de racionalização moderno-ocidental, mostramos que a noção de "cena social" constitui uma ferramenta analítica valiosa para examinar as relações e as interpenetrações das diferentes esferas e o modo como se apresentam as práticas e as interações.

$\mathrm{Na}$ cena de trabalho, entram em jogo, superpõem-se e colidem recursos provenientes do lar, da rua, da política e da escola; os cuidados, como competências (domésticas e femininas) e como critério de questionamento moral dos códigos de interação no trabalho, complementam-se com a submissão, como imagem forjada no espaço familiar, em parte em contraposição à atitude guerreira de honestidade $\mathrm{e}$ de "enfrentar", própria do que alguns autores chamam a "cultura da rua".

Por outro lado, as capacidades associadas à fala è argumentação pública tornam-se uma alternativa estratégica para resolver as disputas abertas no espaço de trabalho. Recursos incorporados que proveem, em certos casos, da reconversão de um capital militante, como competências para se orientar na percepção de diferentes situações, transformam-se em disposiçôes estratégicas para falar ou calar, para atuar ou abster-se, conforme os tempos, o ritmo e o tom das interações nas quais estão envolvidos. Da mesma forma, a construção de situações de trabalho como situações de aprendizagem 
possibilita limitar e regular os exercícios desmedidos de poder na cena do trabalho em contextos de precariedade e instabilidade da dinâmica do mercado de trabalho.

Observamos, assim, uma translação de recursos e de critérios de avaliação desses recursos a partir de homologias que construímos analiticamente entre as cenas doméstica, escolar, política, da rua e a cena específica do trabalho. Essas homologias só podem ser compreendidas levando em conta dois sistemas de relações: um, no contexto do espaço social global, associado à escassez relativa de recursos econômicos e culturais, particularmente desta posição de classe; outro, em cada um dos espaços específicos de autonomia estratégica que podem surgir nas diferentes cenas sociais no interior da própria classe.

A construção da estrutura do espaço social, como distribuição diferenciada de uma multiplicidade de recursos, constitui a condição que possibilita tanto essas homologias quanto as configurações específicas das interações. Por outro lado, a construção de cenas sociais concretas, como tentamos demonstrar, permite descrever diferentes estratégias de gestão de recursos no âmbito do trabalho, no contexto semelhante das condições objetivas da classe.

\section{Referências Bibliográficas}

Assusa, Gonzalo. (2014), "Trabajo, estética de la producción y escenas sociales: etnografías multi-integradas de Florence Weber". Revista Latinoamericana de Metodología de las Ciencias Sociales, 1 (4): 1-5.

Bourdieu, Pierre. ([1979] 1988), La distinción: criterios y bases sociales del gusto. Madri, Taurus. . (1984), "Espace social et genèse des 'clases". Actes de la Recherche en Sciences Sociales, 52-53: 3-14.

. (1986), "L'illusion biographique". Actes de la Recherche en Sciences sociales, 62-63: 69-72.

Bourgois, Phillipe. ([2001] 2010), En busca de respeto: vendiendo crack en Harlem. Buenos Aires, Siglo XXI.

BRUBAKER, Rogers. (1984), The limits of rationality: an essay on the social and moral thought of Max Weber. Londres, Routledge.

Corcuff, Philippe. (2013), Las nuevas sociologias: principales corrientes y debates, 1980-2010. Buenos Aires, Siglo XXI.

Corrigan, Philip \& SAYER, Derek. (2007), "El gran arco: la formación del Estado inglés como revolución cultural”. In: Lagos, María L. \& CAlla, Pamela (orgs.). Antropología del Estado: dominación y prácticas contestatarias en América Latina. La Paz, INDH/PNUD, pp. 39-118.

Duarte, Luiz Fernando. (1994), “A outra saúde: mental, psicossocial, físico moral?”. In: Alves, Paulo César \& Minayo, Maria Cecília de Souza (orgs.). Saúde e doença: um olhar antropológico. Rio de Janeiro, Editora Fiocruz, pp. 83-90. 
(1995), "Pessoa e dor no Ocidente". Horizontes Antropológicos, 9 (4): 12-28.

. (2004) "Las tres configuraciones de la perturbación en Occidente y los nervios de las clases populares". Apuntes de Investigación del CECyP, 9 (8): 75-91.

Durkheim, Émile. ([1893] 1985), La división del trabajo social. Barcelona, Planeta Agostini. Elias, Norbert. ([1970] 1982), Sociología fundamental. Barcelona, Gedisa.

Gutiérrez, Alicia. ([1995] 2012), Las prácticas sociales: una introducción a Pierre Bourdieu. Villa María, Eduvim.

. (2004), Pobré, como siempre... estrategias de reproducción social en la pobreza. Córdoba, Ferreyra Editor.

. (2011), "La producción y reproducción de la pobreza: claves de un análisis relacional". In: Arzate Salgado, Jorge et al. (orgs.). Reproducción de la pobreza en América Latina: relaciones sociales, poder y estructuras económicas. Buenos Aires, CLACSO-CROP, pp. 111-138. \& Mansilla, Héctor. (2015), “Clases y reproducción social: el espacio social cordobés en la última década”. Politica y Sociedad, 2 (52): 409-444.

Habermas, Jürgen. ([1981] 1990), Teoría de la acción comunicativa II: crítica de la razón funcionalista. Madri, Taurus.

HeInich, Nathalie. (1999), Norbert Elias: historiay cultura en Occidente. Buenos Aires, Nueva Visión. LAHIRE, Bernard. (1998), L'homme pluriel: les ressorts de l'action. Paris, Nathan.

Lamont, Michèle. (2000), The dignity of working men: morality and the boundaries of race, class and immigration. Nova York, Harvard University Press.

Lenoir, Remi. (1993), “Objeto sociológico y problema social”. In: Champagne, Patrick et al. Iniciación a la práctica sociológica. Madri, Siglo XXI, pp. 57-102.

Lomnitz, Larissa de. (1978), Cómo sobreviven los marginados. Cidade do México, Siglo Xxi.

LuKÁCs, Georg. ([1923] 1985), "La cosificación y la conciencia del proletariado”. In: Historia y conciencia de clase. Buenos Aires, Orbis, pp. 5-140.

Martín Criado, Enrique. (2008), "El concepto de campo como herramienta metodológica”. Revista Española de Investigaciones Sociológicas, 123: 11-33.

MarX, Karl ([1844] 2004), Manuscritos económico-filosóficos. Buenos Aires, Colihue.

Matonti, Frédérique \& Poupeau, Franck (2004-2005), "Le capital militant: essai de définition”. Actes de la Recherche en Sciences Sociales, 155: 4-11.

SEMÁN, Pablo. (2006), Bajo contínuo: exploraciones descentradas sobre cultura popular y masiva. Buenos Aires, Gorla.

(2007), "Psicologización y religión en un barrio del Gran Buenos Aires". Debates do NER, 12 (8): 8-44.

TÉnÉDos, Julien. (2006), L'economie domestique: entretien avec Florence Weber. Paris, Aux Lieux d'Être.

WeBER, Florence. ([1989] 2009), Trabalho fora do trabalho: uma etnografia das percepçóes. Rio de Janeiro, Garamond. 
. (2001), "Settings, interactions and things: a plea for multi-integrative ethnography".

Ethnography, 2 (4): 475-499.

(2002), "Práticas econômicas e formas ordinárias de cálculo". Mana, 2 (8): 151-182.

Weber, Max. ([1906] 2006), La ética protestante y el espiritu del capitalismo. La Plata, Terramar.

Zelizer, Viviana. (2000), "How and why do we care about circuits". Accounts, 1: 3-5.

\section{Resumo}

Cenas sociais e espaço de trabalho: homologias na vida profissional de jovens de classes populares Neste artigo, analisamos uma série de situações problemáticas em espaços de trabalho nos quais participam jovens de classes populares da cidade de Córdoba (Argentina) e mostramos múltiplas interpenetrações que ocorrem entre os diferentes âmbitos de sua vida cotidiana, especificamente do trabalho. Retomando as noções de "esferas de valor" e "cenas sociais", propomos uma interpretação dos deslocamentos de lógicas de ação e critérios de valor como estratégias de gestão de recursos no espaço de trabalho, possibilitados por homologias estruturais entre diversas cenas sociais (trabalho, família, escola, rua, política) e fundados na estrutura das relações de classe. Palavras-chave: Estratégias; Cenas sociais; Espaço de trabalho; Jovens; Classes populares.

\section{Abstract}

Social scenes and work space: homologies in the working lives of young people from popular classes

In this paper we analyze a number of problematic situations in the working spaces of young people from popular classes in the city of Córdoba (Argentina), and we show many interpenetrations among the different spheres of everyday life and work spaces specifically. Returning to the notions of "value spheres" and "social scenes", we propose an interpretation of movement of logics of action and value criteria as resource management strategies in the workplace, enabled by structural homologies between different social scenes (work, family, school, street, politics) and anchored in the structure of class relations.

Keywords: Strategies; Social scenes; Work space; Young people; Popular classes.

Texto recebido em 21/7/2014 e aprovado em 12/12/2014. DOI: 10.11606/0103-2070. ts.2016.106225.

Alicia Beatriz Gutiérrez é pesquisadora independente do Consejo Nacional de Investigaciones Científicas y Técnicas (Conicet) e professora titular de sociologia na Universidade Nacional de Córdoba.E-mail: gutierre@ffyh.unc.edu.ar.

Gonzalo Assusa é bolsista do Conicet e doutorando em antropologia na Universidade Nacional de Córdoba.E-mail: gon_assusa@hotmail.com. 